\title{
Management of Hydrocephalus
}

\author{
Parvaneh Karimzadeh \\ Pediatric Neurology Department, \\ Shahid Beheshti University of Medical Sciences, \\ Pediatric Neurology Research Center, \\ Tehran \\ Iran
}

\section{Introduction}

Hydrocephalus is a problem in which there is an excessive contains of cerebrospinal fluid (CSF) and dilates cerebral ventricles.

Regardless of etiology, early detection and early intervention of this condition is very important to prevent brain insult and normal development of children.

Decrease of this volume accumulation and pressure maintain normal chemical balance and normal function of blood-brain barrier.

In progressive symptomatic hydrocephalus patients have the symptom of intra cranial hypertension.

\section{Surgical management}

If there is obstructive or non-communicating hydrocephalus removal the obstruction is preferred.

In progressive symptomatic hydrocephalus surgical intervention such as shunting of cerebrospinal fluid to facilitate absorption of CSF is required.

Most patients need mechanical extra cranial shunt system for redirect cerebrospinal fluid circulation into peritoneal cavity, right atrium and pleural cavity.

\section{Ventriculoperitoneal shunting}

A ventriculoperitoneal shunt (VP) is used most commonly for cerebrospinal fluid diversion.

The abdomen should have the ability for absorption of the fluid. Shunts cause cerebrospinal fluid to flow unidirectional under a valve system. Pressures required enough energy to overcome valve resistance and can be used in patients with different pressure requirements.

The ventricular catheter can be placed from the coronal approach. In this approach most neurosurgeons prefer parieto-occipital catheters. The proximal catheter tip should lie anterior to choroid plexus and in the frontal horn of the lateral ventricles. 


\section{Complications}

Common causes for failure are: infection, obstruction, over drainage, disconnection and loculated cerebrospinal fluid collection (1).

For evaluation of shunt malformation continuous intra cranial monitoring is useful. Main complication of this type of treatment is infection and the most important causative agents of infection are staphylococcus epidermitis (58\% to $88.9 \%)$, Staphylococcus aureus (12-40\%), gram negative bacilli (9-22\%), entrobacteria, klebsiella pneumonia and pseudomonas aeroginosa. These can cause severe complications such as cognitive and neurological deficits (1-4).

If infection causes impairment of the shunting mechanism, removal and new shunting system are necessary.

Prophylactic antibiotics during shunting decrease the incidence of infection.

As there is a great preponderance of the skin agents in these infections considering of Vancomycin plus third or fourth generation Cephalosporin like cefteriaxon as empiric treatment until cultures are obtained is an appropriate treatment.

Dysfunction of the hydrocephalus valve is also another serious cause of complication and it's a result of the obstruction of proximal catheter.

Over drainage of CSF is another long term complication of cerebrospinal fluid shunting. This complication and obstruction need more surgery.

\section{Ventriculoatrial shunting}

This procedure usually is the first choice for patients who are unable to have abdominal distal catheters. It is a high risk procedure with possibility of serious long term complications such as renal failure or thrombosis of great vein.

An incision is made across the anterior border of the sternocloidomastoid muscle to expose the jugular vein. Alternately, the shunt can be placed in the common facial vein just as it enters the jugular vein. Once the jugular vein is isolated with ligatures, the vein is tied off distally.

A small opening is then made into the jugular vein to pass the shunt into the right atrium of the heart. Ventriculo-atrial shunts may occlude due to thrombus formation, if the distal end moves out of the atrium (4-5).

\section{Endoscopic Third Ventriculostomy (ETV)}

ETV is an alternative therapy to cerebrospinal fluid shunting in selected patients.

This method is a selective surgical management in patients with congenital aqueduct stenosis.

Also ventriculostomy is useful for patients with intracranial cysts and local cerebrospinal fluid collection.

Overall the failure rate of different shunt is approximately $40 \%$ in the first year after surgery (6). 
It is a minimally invasive procedure which is used in children with obstructive hydrocephalus (such as aqueduct stenosis or tumor) that have normal or near normal spinal fluid as an alternative to shunt revision (7-8).

The goal of ventriculostomy is to create an opening in the floor of the third ventricle to subarachnoid space, usually the trapped fluid begin to absorb right after the opening, in that case there is no need for further interventions.

This surgery takes only one hour and the neurosurgeon uses a tiny camera and a minute surgical instrument and will follow the child regularly after undergoing ETV to make sure of normal intracranial pressure and no complications occur. Third ventriculostomy is divided into several stages. After general anesthesia is induced, the patient is placed supine with the head in the neutral position on a doughnut pillow. The head is then elevated approximately $30^{\circ}$ to minimize excessive CSF loss and entry of air. A coronal burr hole is placed $3 \mathrm{~cm}$ lateral to the midline and just anterior to the coronal suture.

The stages of this operation are:

- finding and entering the foramen of Munro

- Inspecting the floor of the third ventricle

- Perforating the floor of the third ventricle

- Enlarging this perforation

- Inspecting the prepontine cistern (9)

- Advantages

- No foreign objects (shunt tubing and valve) implanted in the body, minimizing the risk of infection.

- $\quad$ Fewer incisions cause less discomfort.

- A lower long term complication rate compared to a shunt.

- Disadvantages

- The chances of improving may be lower in comparison with shunting

- Although very unlikely, there is a risk of serious complications with ETV compared to a shunt operation.

\section{Complications}

Neurosurgeons have accepted Endoscopic third ventriculostomy as a choice procedure for the treatment of obstructive hydrocephalus especially in children.

The success of the procedure depends on the cause of hydrocephalus and past complications.

The most common complications of endoscopic third ventriculostomy are fever and bleeding. The use of a cold light source and a monopolar coagulation in the confined volume of the third ventricle can increase CSF temperatures to high levels, sometimes causing fever. Attempts to perforate the ventricular floor can lead to bleeding, as can damage to ventricular walls or perforation of the basilar artery.

Fever up to $40^{\circ} \mathrm{C}$ within 3 days after ventriculostomy within clinical or laboratory tests of meningitis, meningitis with fever and clinical \& positive findings of CSF, occurrence of very mild hemorrhage from free edge of stoma, mild hemorrhage from ependymal veins, moderate to severe intraventricular hemorrhage were considered as the most common complications. 
Short-term memory loss is another potential complication of endoscopic third ventriculostomy, since the procedure may affect the hypothalamus, which is responsible for memory. However, given time, an individual usually recovers from any short-term memory loss following endoscopic third ventriculostomy.

Other Complications of ETV could leakage of CSF, bradycardia, loss of thirst, increased appetite, subdural hematoma, injury to periventricular structures such as hypothalamus which can result diabetes inspidus.(7)

According to Canadian Pediatric Neurosurgery Study Group about the Canadian experience in Endoscopic third ventriculostomy (in children) age has a significant effect on outcome in pediatric patients.

Canadian pediatric neurosurgery study group evaluated age, sex, etiology of hydrocephalus and history of previous surgery and finally found failure rates are particularly high in young infants, therefore, this procedure in neonates and early infants should be carefully considered (8).

\section{Factors associated with outcomes in ETV}

The outcome of this procedure remains controversial regards to etiology, age and long term complications.

The most controversial issue is the lower age limit for affectivity of this procedure.

The best results were reported in patients with posterior fossa tumor or pineal glioma . The next priority is the cases with Aqueductal stenosis.

Fewer good outcomes were seen in post hemorrhagic hydrocephalus and in chronic cases with hydrocephalus.

Also patients with myelomeningocele and post meningitis hydrocephalus had poor outcomes (9).

\section{Non surgical management}

Non surgical management is treatment of symptomatic hydrocephalus and includes the temporary use of medications to decrease CSF production such as Acetazolamide or Isossorbide which produce hyper osmotic diuresis and increases CSF absorption (10).

In premature infants hydrocephalus may develop as a result of intraventricular hemorrhage. This intraventricular hemorrhage causes obstruction of arachnoid granulations by production of materials reminder from break down of hemorrhage. Shunting has high morbidity in premature infants.

Multiple other interventions have been considered. One of these interventions is lumbar punctures.

Repeated lumbar punctures CSF are a common non surgical management in premature infants to periventricular dilation after periventricular hemorrhage. They believe removal of CSF with blood and protein (approximately 10 to $15 \mathrm{ml} / \mathrm{kg}$ ) causes normal resorption of CSF to prevent the development of hydrocephalus after periventricular hemorrhage. Despite few studies support this method, other studies revealed the repeated lumbar puncture did not reduce the need for shunting of cerebrospinal fluid and also this method did not decrease the likelihood of dead or disability in these patients. 
Some studies showed a higher incidence of cerebrospinal fluid infections in those premature infants who received repeated lumbar punctures for intraventricular hemorrhage (11).

In this procedure the child is getting immobile and a minute needle is placed in Childs lower back and the CSF is removed.

Some studies recommend cerebrospinal fluid tapping in specific situations and by some expert physicians; they consider a sufficient quantity of CSF for these premature infants (about $10-15 \mathrm{ml} / \mathrm{kg}$ ).

Other studies have examined direct ventricular drainage in patients with rapidly progressive ventriculomegaly who their brain ventricles are too small to shunt the ventriculoperitoneal shunt placement (12-13).

It has the relative risks for shunt placement, death disability and multiple disabilities were similar for repeated lumbar punctures.

In progressive hydrocephalus serial lumbar punctures may be needed until the infant is large enough for permanent placement.

\section{Rehabilitation}

Regardless of different surgical management patients with hydrocephalus have some disabilities such as: learning disorder, behavioral problems, and speech delay.

Early intervention with different methods of rehabilitation is necessary for non surgical management of patients with hydrocephalus.

Successful shunting is usually related to more obvious and rapid improvements in rehabilitation efforts and rapid improvements in rehabilitation efforts (14).

\section{Physical therapy interventions}

Physical therapy goals for child with hydrocephalus appropriates functional skills and reducing secondary impairment such as contractures, fractures and obesity which could interfere with developmental skills .the physiotherapist can work with child in home hospital or clinic depending on the age and medical conditions.

\section{Fetal ventriculomegaly and hydrocephalus}

Fetal ventriculomegaly is a relatively common finding on second trimester obstetrical ultrasound examination (15). Most experts define fetal ventriculomegaly as a lateral ventricular atrial measurement of greater than $15 \mathrm{~mm}$.Ventriculomegaly is "isolated" when the fetus has no other anomalies (15-16). The prevalence of ventriculomegaly is less than 2 percent, but reports vary widely within that range (17).

The preferred diagnostic technique for assessing ventriculomegaly is ultrasound measurement of the diameter of the lateral ventricles at the level of the atria. The ventricle should be measured in the axial plane, at the level of the frontal horns and cavum septi pellucidi.

The outcome of ventriculomegaly depends on several factors including the actual size of the ventricles, whether or not there are any other findings on the ultrasound, such as agenesis of 
the corpus callosum, and the results of the amniocentesis. In general, the outcome is worse when the ventricles are larger, the amniocentesis is abnormal, or there are other problems seen on the ultrasound.

The best outcome is typically observed when the fetus' ventricles are only mildly enlarged (measure between 10-15 millimeters in size), and when there are no other problems seen on the ultrasound, and when genetic testing results are normal-this is called "Isolated Mild Ventriculomegaly". The most common effect in the child is developmental delay. This seems to be related to the size of the ventricles.

\section{References}

[1] Lima MM, Pereira CU, Silva AM. Infeç̧es em dispositivos neurologicos implant veis em crianças e adolescentes.Arq Neuropsiquiatr 2007; 65(1):118-123.

[2] Paiva WS, et al. Management of the ventriculoperitoneal shunt infections Rev Panam Infectol 2010;12(3):43-47.

[3] Lima MM, Pereira CU, Silva AM. Infeç̧es em dispositivosneuroĺgicos implant veis em crianças e adolescentes. Arq Neuropsiquiatr 2007; 65(1):118-123.

[4] Raza Rizvi, Qudsia Anjum. Hydrocephalus in Children .J Pak Med Assoc Vol. 55, No. 11, November 2005.

[5] Hydrocephalus surgery. copied 2010 available at URL:http:/ /hydrocephalus.allanch.dk.

[6] Drake JM, Kestle JR, Milner R,et al.Randomized trial of cerebrospinal fluid shunt valve design in pediatric hydrocephalus,Neurosurgery 1998;43:294.

[7] Marvin A fishman, MD.Hydrocephalus.2011 available at URL: http:/ / uptodate.com.

[8] George I. Jallo, M.D., Karl F. Kothbauer, M.D., and I. Rick Abbott, M.D. Endoscopic Third Ventriculostomy: Technique Neurosurg Focus. 2005; 19(6)

[9] Drake, James M.F. Endoscopic Third Ventriculostomy in padiatric patients, The 25 Canadian Experience, Neurosurgery , May 2007, 60(5) 881-886

[10] Alberto J Espay, MD; available at URL: http://emedicine.medscape.com/article/ 1135286-treatment Updated: Apr 27, 2010.

[11] Whitelaw A. Repeated lumbar or ventricular punctures in newborns with intraventricular hemorrhage. Cochrane Database Syst Rev 2001;CD000216.

[12] Berger A, Weninger M, Reinprecht A, et al. Long-term experience with subcutaneously tunneled external ventricular drainage in preterm infants. Childs Nerv Syst 2000; 16:103.

[13] Heep A, Engelskirchen R, Holschneider A, Groneck P. Primary intervention for posthemorrhagic hydrocephalus in very low birthweight infants by ventriculostomy. Childs Nerv Syst 2001; 17:47.

[14] Bontke CF, Zasler ND, Boake C. Rehabilitation of the head-injured patient. In: Narayan RK, Wilberger JE, Povlishock JT, eds. Neurotrauma. New York, NY: McGraw-Hill; 1996:841-58.

[15] Griffiths PD, Reeves MJ, Morris JE, et al. A prospective study of fetuses with isolated ventriculomegaly investigated by antenatal sonography and in utero MR imaging. AJNR Am J Neuroradiol 2010; 31:106.

[16] Davis GH. Fetal hydrocephalus. Clin Perinatol 2003; 30:531.

[17] Partington MD. Congenital hydrocephalus. Neurosurg Clin N Am 2001; 12:737. 


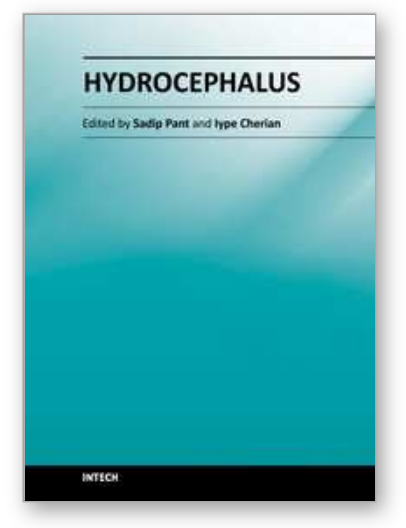

\author{
Hydrocephalus \\ Edited by Dr Sadip Pant
}

ISBN 978-953-51-0162-8

Hard cover, 214 pages

Publisher InTech

Published online 24, February, 2012

Published in print edition February, 2012

Description of hydrocephalus can be found in ancient medical literature from Egypt as old as 500 AD.

Hydrocephalus is characterized by abnormal accumulation of cerebrospinal fluid (CSF) in the ventricles of the brain. This results in the rise of intracranial pressure inside the skull causing progressive increase in the size of the head, seizure, tunneling of vision, and mental disability. The clinical presentation of hydrocephalus varies with age of onset and chronicity of the underlying disease process. Acute dilatation of the ventricular system manifests with features of raised intracranial pressure while chronic dilatation has a more insidious onset presenting as Adams triad. Treatment is generally surgical by creating various types of cerebral shunts. Role of endoscopic has emerged lately in the management of hydrocephalus.

\title{
How to reference
}

In order to correctly reference this scholarly work, feel free to copy and paste the following:

Parvaneh Karimzadeh (2012). Management of Hydrocephalus, Hydrocephalus, Dr Sadip Pant (Ed.), ISBN: 978-953-51-0162-8, InTech, Available from: http://www.intechopen.com/books/hydrocephalus/managementof-hydrocephalus-

\section{INTECH}

open science | open minds

\section{InTech Europe}

University Campus STeP Ri Slavka Krautzeka 83/A 51000 Rijeka, Croatia Phone: +385 (51) 770447 Fax: +385 (51) 686166 www.intechopen.com

\section{InTech China}

Unit 405, Office Block, Hotel Equatorial Shanghai No.65, Yan An Road (West), Shanghai, 200040, China 中国上海市延安西路65号上海国际贵都大饭店办公楼 405 单元 Phone: $+86-21-62489820$

Fax: $+86-21-62489821$ 
(C) 2012 The Author(s). Licensee IntechOpen. This is an open access article distributed under the terms of the Creative Commons Attribution 3.0 License, which permits unrestricted use, distribution, and reproduction in any medium, provided the original work is properly cited. 